\title{
The Syntax of Dholuo Anaphors and Case Assignment
}

\author{
Janet A. Onyango ${ }^{1}$, Henry S. Nandelenga ${ }^{2}$, Emily A. Ogutu ${ }^{1}$ \\ ${ }^{I}$ Department of Linguistics, Literature \& Foreign Languages, Kenyatta University, Kenya \\ ${ }^{2}$ Department of English, Literature \& Journalism, Kibabii University, Kenya \\ DOI: https://dx.doi.org/10.47772/IJRISS.2021.5407
}

\begin{abstract}
Anaphors which include the reflexive and reciprocal manifest differently in languages all over the world. As referent items, they occur as morphological, syntactic or lexical. In this paper, a different focus is taken by assignment of case to determine grammaticality of sentences that contain anaphors. Data was drawn from native speaker intuition and secondary data from scholars. The data was subjected to validation by being verified by six adult native speakers. Different types of anaphors collected were analyzed using descriptive and qualitative research designs. Case Theory, a module of Government and Binding Theory was used as the tool for analysis. The analyses report that Dholuo language exhibit both lexical and non-lexical words as anaphors which occupy object position. The non-lexical anaphor $-r$ 'self' or 'each other', does not occur in isolation; it is attached to the verb and followed by a personal pronoun. It is also established that Dholuo anaphor is assigned morphological accusative case by the verb, the antecedent is assigned abstract nominative case by INFL(ection); while the preposition assigns oblique case to its object to satisfy the case filter principle. However, Exceptional Case marking (ECM) occurred where the anaphor in an infinitival IP was exceptionally assigned accusative case by the verb from the matrix. But, where the Complementizer Phrase (CP) and Prepositional Phrase (PP) occurred, ECM does not apply since they are barriers to government. Conversely, Case Theory could not account for assignment of case to an extra anaphor in the sentence like wuon 'self' in Dholuo that occurred with the anaphor $-r$ 'self' 'each other. Therefore, there is need for a linguistic theory that captures the assignment of case to two anaphors that occur in constructions.
\end{abstract}

Keywords: anaphors, antecedent, case, case filter, grammaticality

\section{INTRODUCTION}

A naphors are elements that refer back to other elements in a construction, and they need to be close to the elements they refer to [11], [21]. They function referentially only when they interact with the antecedent in the same sentence. According to [16], anaphors are exhibited differently in many languages in the world. They can occur as morphological (non-lexical), syntactic or lexical items. The anaphor and the antecedent, an element that occurs before the anaphor in the same minimal inflectional phrase (IP) must corefer. This reference is indicated by use of a subscript placed on the anaphor and the antecedent. The anaphors constitute elements that bear the feature [+Anaphor, -Pronominal] during their interpretation. Within the Government and Binding Theory, anaphors are of two types: reflexives and reciprocals [21]. These anaphors are interpreted using Binding Principle A which posits that an anaphor must be bound within its governing category. The governing category is the domain in which the anaphor occurs. The antecedent, therefore, governs the anaphor in the same minimal IP. In this paper, the focus is on describing these anaphors, and evaluate how they are assigned case by case assigners.

A number of related studies on anaphors in Dholuo have been done. [14] identified the different syntactic structures of Dholuo. The study focused on the Transformational Grammar by Chomsky. The study identified two types of reflexives in Dholuo: the generative or impersonal -ruok 'self' a suffix attached to the verb and a morpheme $-r$ 'self' followed by a personal object pronoun. Another study, the syntactic and semantic relation of Dholuo anaphors tested Chomsky's binding principles [15]. The study demonstrated presence of two categories of anaphors: overt anaphors (reflexives and reciprocals) and covert anaphors (PRO) which comprised of an argument in the sentence. The argument could be a subject or object in the sentence. On the other hand, a study by [18] posit that Dholuo has two types of anaphors categorized as true reflexives and reciprocal constructions. Okoth observed that the true reflexive is marked by the morpheme $-r$ followed by a personal pronoun. Okoth viewed the use of the impersonal -ruok as an element that relied on the intuition in translating the English infinitival phrase.

Similarly, [20] identified two types of anaphors to include reflexives and reciprocals. The use of reflexive and reciprocal was noted to be ambiguous and needed context to disambiguate since they are marked by the same morpheme. In addition, [26] focused on long distance anaphors in Dholuo which are elements that function as anaphors in sentences. The study discovered that these long distance anaphors (pronominals) in Dholuo violate Binding Principle A and in most cases are ambiguous. In this paper, analysis is on anaphors that obey Binding Principle A even as they occur in different positions, and also assignment of case to the anaphor and its antecedent to determine the grammaticality of the sentences. Data is based on Dholuo anaphors such as reflexives, reciprocals, anaphoric pronouns, anaphoric demonstratives, inherent and body parts anaphors.

In the same vein, a plethora of research has been done on anaphors in a number of Romance languages like Italian, Spanish, Romanian and Portuguese. These languages indicate occurrence of anaphors which might exhibit some similarities 
or differences with Dholuo anaphors. According to [13], in Italian, the reflexive 'self' is marked by $s i$, Spanish and Portuguese marks the reflexive by se while in Romanian by się. The reciprocal 'each other' is marked by se in Spanish and Portuguese while Italian marks the reciprocal by si. The difference between the use of $s i$ for reflexive and reciprocal in Italian is based on the position of the anaphor. In Spanish, the morpheme marking the reciprocal appears as an independent lexical item while in Portuguese the morpheme marking the reciprocal is bound to the verb. The reflexive si and reciprocal se are inflected for person and number. This data on Romance languages is key as it highlights the configuration of anaphors which is also reflected in Dholuo language. For instance, Spanish and Portuguese mark the reflexive and reciprocal using the same morpheme just like Dholuo which uses the same morpheme to mark both anaphors. On the contrary, a difference occurs between Spanish and Dholuo in that the morpheme that marks the reciprocal in Spanish appears as an independent lexical item while in Dholuo, it is bound to the verb. However, the similarity is that in both Romance languages and Dholuo, the anaphors are inflected for person and number. Consider the data (1) from Romance languages: (1)

a. Maris si guarda.

(Italian)

Maria si watches

'Maria watches herself.'

b. Sarebe bello [PRO vedersi più spesso]. (Italian)

Would be nice [PRO see si more often]

'It would be nice to see each other more often.

c. Juan se lavó.

(Spanish)

Juan se washed

'Juan washed (himself).'

d. Los padre se despidieron

(Spanish)

The parents se said goodbye

'The parents said goodbye to each other.

e. Os meninos insultaram-se

(Portuguese)

The children insulted-se

'The children insulted themselves/ each other.

f. Janek ubiera się

(Romanian)

John dresses się

'John gets dressed.' [13]

Data (1) from Romance languages indicate that the reflexive is marked by se or si and the reciprocal is also marked by se or $s i$. The se reflexive markers in Romance languages appear as free morphemes, not attached to the verb stems they are combined with. This is contrary to Dholuo where the reflexive and the reciprocal are marked by the same morpheme $-r$ (see 2.1).

Another study of interest is on anaphors among the Bantus, an African language. For instance, [25] studied anaphors in Lubukusu, a Luhya dialect in Western Kenya. The study focused on the syntactic patterns of anaphors, that is, reciprocals and reflexives. [25] considered the anaphors as incorporated pronouns with the status of arguments. Thus they are analysed the same way as other arguments. This line of thought is taken in the analysis of Dholuo anaphors which exhibit the same characteristics and appear as arguments though this study will not refer to them as incorporated pronouns. Lubukusu marks the reflexive and the reciprocal differently in sentences. The reflexive in Lubukusu is marked morphologically by the affix $-e$ and $-i$ 'self' that occur as allomorphs. The morphological reflexive marker in Lubukusu can be equated to Dholuo morphological reflexive $-r$. Though, the difference between Lubukusu and Dholuo reflexive is that in Dholuo the reflexive does not occur as an allomorph. Another difference is that the occurrence of any reflexive marker is determined by phonological factors in Lubukusu, while in Dholuo it is determined by persons. Let's consider data (2) (2)

a. Yohana a-a-e-bona-a

John past self see

'John saw himself.'

b. Mu-a-e-bon-a

You(pl)self see

'You saw yourselves.'

c. W-i-siing-ang-a

You(sg) self see

You washed yourself.'

[25]

Examples (2a) - (2c) indicate that the reflexive marker is either $-e$ or $-i$ and it is attached before the verb. This information is vital in the analysis of Dholuo reflexive which occurs after the verb and is attached to the verb followed by different persons. On the other hand, the reciprocal in Lubukusu is marked differently from the reflexive as seen in example (3) below. The reciprocal is marked by the suffix -an 'each other' with no allomorph. The -an reciprocal occurs after the verb followed by a final vowel. This is contrary to Dholuo that marks the reciprocal the same way as the reflexive. In order to differentiate the reflexive and reciprocal in Dholuo, context of usage which is pragmatics must be considered. The evidence of the occurrence of - an reciprocal in Lubukusu is compared with other Bantu languages like Kiswahili that marks the reciprocal the same way. This is demonstrated in (3): (3) 
a. Babaana ba-a-rem-an-a

(Lubukusu)

children cut each othe

'The children cut each other.'

b. Watoto wa-li-pig-an-a

(Kiswahili)

children hit each other

'The children hit each other.'

Examples (3a) and (3b) show that Bantu languages mark the reciprocal the same way with the suffix -an followed by a final vowel [a]. In the same vein, Dholuo marks the reciprocal by attaching the morpheme after the verb like the Lubukusu, but followed by a personal pronoun as will be demonstrated in section 2 .

In this paper, Case Theory a module of Government and Binding Theory is used in analysing anaphors syntactically. Case Theory deals with properties that noun phrases have and their distribution in a sentence. The theory accounts for some formal properties of overt NPs (lexical and non-lexical), and case in grammar. The theory stipulates that all overt NPs be case marked. According to [11], case refers to the relationship a noun has with other words, or the change of form by which relation is indicated. If the noun phrase lacks the feature, it is said to be ungrammatical. The nature of abstract case relations and their realizations, which is morphological are shown and assigned case markers [1], [21]. This indicates that there is relationship between morphological and abstract case in that morphological case is a realization of the abstract case [21]. The different forms that the argument assumes are assigned morphological case. These forms relate to the main form of the argument that does not change form in various positions and so is assigned abstract case.

In addition, Case Theory allows assignment of different cases. These include, nominative case, accusative case and oblique case. The changes in the form of a word determines the case to be assigned to it. For instance, a noun in a subject position is assigned a nominative case, in an object position is assigned an accusative case. If the noun is the object of a preposition, it is assigned an oblique case [21]. The element assigning case is the assignor while the element being assigned case is the assignee. The case assignors are INFL(ection) (I), verb and preposition. The accusative case is assigned to the complement of the verb, unless the verb is marked to assign or check for another case. The nominative case is assigned to the specifier (NP) by INFL, while oblique case is assigned to the object of the preposition. Case assignment is guided by the case filter principle which stipulates that an NP must be assigned case [21]. In order to explicitly explain the assignment of case, some notions of Government Theory are included such as government and minimality condition. The heads are governors of the elements they m-command and to which they assign case. Besides, there are special heads that assign case to their governors which is dealt with in Exceptional Case Marking (ECM).

\section{METHODOLOGY AND FRAMEWORK}

Data was collected through the researcher's intuition as a native speaker and verified by six respondents selected using purposeful technique. The assumption was that native speakers have inherent native speaker competence which detected what was well and ill formed in the language. A semi-structured, in-depth one-to-one interview was conducted with all the six respondents at different times. Descriptive research method was employed where corpus of data was procedurally analyzed to investigate the structure of the language. Qualitative research design was also employed by reviewing secondary data documents which were incorporated in the descriptive analysis.

\section{ANALYSIS AND INTERPRETATION}

\subsection{Dholuo Anaphors}

Dholuo anaphors occur as reflexives and reciprocals. As earlier mentioned, the reflexive and reciprocal in Dholuo are marked the same way. In addition, there are other elements that function as anaphors in Dholuo as will be discussed in the subsequent subsections.

\subsubsection{Reflexives and Reciprocals}

The anaphors are expressed cross-linguistically by different word categories such as adverbs, pronouns, and also bound morphemes among other morphemes. [16] states that there are different types of reciprocals which include the morphological, syntactic and lexical reciprocals. In Dholuo, anaphors are expressed both morphologically and lexically. Morphologically, the anaphor which is non-lexical in Dholuo appears as the morpheme $-r$ 'self' or 'each other' which is followed by a personal pronoun attached to the verb. This morpheme $-r$ represents both the reflexive and the reciprocal. Table 1 represents Dholuo anaphor and different persons that it can be attached to:

Table I: Dholuo Anaphors

\begin{tabular}{|c|c|c|}
\hline Person & Singular & Plural \\
\hline First person & -ra & -re \\
\hline Second person & -ri & -ru \\
\hline Third person & -re & -re \\
\hline
\end{tabular}

From table 1, we note that Dholuo anaphor assumes different persons. These anaphors agree in number and person with the antecedent in the sentence. This is demonstrated using data (4) below: (4)

a. Apondi $\mathrm{A}_{\mathrm{i}}$ ohero-re $_{\mathrm{i}}$

Apondi loves self

'Apondi loves herself.'

b. Akinyi ${ }_{i}$ ohero-re ${ }_{i}$ ahinya 
Akinyi love self much

'Akinyi loves herself so much.'

c. Bul go-re $_{\mathrm{i}}$ oko

drum beat self outside

'The drum is beating itself outside.'

d. Mine $_{i}$ ohero limo-re ${ }_{i}$.

Women love visit each other

'Women love visiting each other.'

e. $\mathrm{Jogo}_{i}$ pidho-re $_{\mathrm{i}}$ chiemo.

People those feed each other food

'Those people are feeding each other food.'

From the data, (4a), (4b) and (4c) are cases of reflexives used in Dholuo constructions; while (4d) and (4e) are instances of the use of reciprocal. The anaphors are bound to the verb by being coindexed to indicate the action being performed. The reflexive $-r e$ 'self' is attached to the verb hero 'love' in (4a). In (4a), Apondi the antecedent performs the act of loving to herself and not any other person. Example (4b) shows that the subject, Akinyi performs the act of loving herself so much thus the emphasis of 'ahinya' 'so much' and not any other person. In (4c), the reciprocal is marked by -re 'each other' attached to the verb go 'beat' to indicate that the act of the drum beating itself is happening outside a building. This action also shows the extent to which the drum is being beaten. In (4d), the women have the tendency of visiting each other. So, the women perform the act of visitation to each other. Lastly, in (4e), the people are performing the act of feeding to each other.

Moreover, there are lexical words in Dholuo that function as anaphors in the sentence. [26] refer to such anaphors as long distance and they include personal pronouns and demonstrative pronouns. In addition, there are nouns that function as anaphors that refer to different body parts like the head, body and soul [23]. Again, there are anaphors that refer to the action happening to self-known as inherent anaphors. Section 3.1.2 elaborates on the use of these anaphors.

\subsubsection{Inherent and Body Parts Anaphors}

To begin with, the inherent anaphors refer to anaphors that indicate an action happening to self. These inherent anaphors in Dholuo are represented by the morpheme $-r$ followed by the person or lexical words that function as anaphors. The emphasis is on the reference to 'self'. Let us consider (5) (5)

a. Mpira ong'ielore kochiko pap.

Ball roll self towards field

'The ball rolled itself towards the field.'

b. Apondi olielore.
'Apondi shove herself.'

c. Apondi olielo tike.

Apondi shave beards

'Apondi shove her beards.'

d. Apondi olielore gi makas.

Apondi shave with scissors

'Apondi shove herself with scissors.'

e. Oyuere.

$\mathrm{He} /$ she wipe self

'He/she wipes herself/himself.'

f. Oyueyo dende gi taulo.

$\mathrm{He} /$ she wipe body with towel

'He/she wiped his/her body with a towel.'

In example (5a), the action of mpira 'ball' rolling happens to itself with the direction given kochiko pap 'towards the field'. Whether someone initiated the process of rolling is not known. But, the fact that the ball is rolling indicates that the ball is the subject, antecedent affected by the action of rolling. In (5b), the person Apondi who is the antecedent performs the action of lierore 'shaving herself'. The part of the body being shove is not indicated, neither is the tool used to shave mentioned. What is important is that the action of shaving happens to the antecedent Apondi. (5c) gives detailed account of the part of the body being shove, tike 'beard'. The pronoun $-e$ 'his' refers back to Apondi who is the antecedent. (5d) explicitly provides information on the act of Apondi shaving herself and specifically using makas 'scissors'. (5e) provides an instance of someone wiping himself or herself. The reflexive $-r e$ refers to this person. (5f) indicates that the person wipes his body dende. The pronoun $-e$ 'his/her' refers back to the person performing the act of wiping himself or herself. This act is done using a towel and not any other thing.

Moreover, in (5a) mpira ong'ielore kochiko pap 'the ball rolled towards the field' refer to the fact that the reflexive -re attached to the verb $n g$ 'ielo 'roll' indicate that the antecedent mpira 'ball' performed the act of rolling to itself towards the field. In (5b), Apondi olierore, 'Apondi shove herself' the antecedent Apondi performed the act of shaving on herself. (5c) Apondi lielo tike 'Apondi shove her beard' specifies the actual part of the body that Apondi shove, that is the beard. (5d) Apondi olielo tike gi makas 'Apondi shove her beard with a scissor' indicates that Apondi shove herself and the tool used was a scissor. (5e) oyuere 'he/she wiped himself/herself' indicates in general that the person wiped himself or herself and this could be any part of the body. (5d) oyueyo dende gi taulo 'he/she wiped his body with a towel' shows the person wiped specifically his or her body with an instrument taulo 'a towel'.

Apondi shave self 
Secondly, body part anaphors consist of reflexives and reciprocals that are related to body part nouns like the head, body and soul [24]. The body part reflexives are common across languages as noted by [23]. In the same vein, [25] allude to the fact that African anaphors exhibit a complex lexical form which consists of two or more forms which could mean body, body part or self and another one being the agreeing pro-form. [23] mentions that the concept of self as in reflexives is intrinsic in individuals, hence refers to the person. This is different to other nouns such as mountain, tree or cat, but same as the nouns like head, body or soul. The body part anaphors in Dholuo are presented in (6) below: (6)

a. Omondi ohinyore.

Omondi hurt body/self

'Omondi hurt himself.'

b. Achwanyora.

I hurt soul/body/self

'I hurt myself.'

c. Ruth oneno buk toke.

Ruth see book body

'Ruth saw a book behind her.'

d. Nyithindo onenore.

Children see body

'Children saw each other.'

e. Nyiri oherore

Ladies love body/soul/each other.'

'The ladies love each other.'

In example (6a) the reflexive $-r e$ 'self' refers to the person Omondi (antecedent) who could have hurt part of his body due to an accident or his soul as a result of an occurrence. Example (6b) means the reflexive $-r a$ 'myself' refer to the fact that the person a- 'I', antecedent could have hurt part of his or her body. It could also mean that the person's soul got hurt because of an occurrence. In example (6c), the pronoun $e$ 'his' attached to the noun toke 'back' is part of the body and it refers back to the antecedent Ruth who saw the book. The anaphor -re 'themselves' or each other' in example (6d) refer to the antecedent nyithindo 'children' who saw body parts of themselves or each other's body part. In (6e), the anaphor -re 'themselves' or 'each other' refer back to the antecedent nyiri 'ladies' and it implies that the ladies love their own body or soul; or that the ladies love each other's soul or body.to the act of the ladies loving each other's body or their soul which is exhibited through their action to one another.

\subsubsection{Dholuo and Related Anaphors in Nilotic Languages}

African languages exhibit the existence of anaphors [16]. There are many Nilotic groups, but this paper focuses on the
Ateso and Maasai, Eastern Nilotic groups. These two Nilotic groups have anaphors that indicate some similarities and differences with Dholuo anaphors. First, data from Ateso an Eastern Nilotic language spoken by the Iteso people in Uganda and Kenya gives an account of the anaphors [6]. The reflexive in the Ateso is marked lexically by akwan 'self' which appear independent and followed by a personal pronoun. On the other hand, the reciprocal appears as an allomorph akin or okin 'each other' where by their usage depends on phonology [6]. Reference [16] further argues that the Ateso reciprocal require the presence of at least two participants who are affected by the action of the verb [16]. Let's consider (7):(7)

a. Emusung ong akwan $\mathrm{ka}_{\mathrm{i}}$

Hurt myself I

'I hurt myself.'

b. Imusung ijo akwan $\mathrm{kon}_{\mathrm{i}}$

Hurt you self you

'You hurt yourself.'

c. E-mal ${ }_{i}$-akin ${ }_{\mathrm{i}}$-a-si

greet girls each other

'The girls greeted each other.'

d. A-kik ${ }_{\mathrm{i}}$-okin $\mathrm{i}$-osi

Bruise each other

'to bruise each other.'

In examples (7a) and (7b), the reflexive akwan 'self' an independent lexical item comes after the objects ong 'my' and ijo 'you' respectively. The action being performed by the verb musung 'hurt' and the subject affected by the action of verb $k a$ 'I', kon 'you', appears after the reflexive. The reciprocal in (7c) akin and (7d) okin 'each other' which are allomorphs occur as morphemes bound to the verb. The anaphors in Ateso corefer with the subject since they are participants in the same world of discourse [16]. Ateso has different markers of reflexive and reciprocal unlike Dholuo that has one marker for both. The similarity is based on the fact the anaphors in Ateso are dependent on the person just like in Dholuo.

Similarly, data from Maasai, a Nilotic language spoken in Kenya and Tanzania indicate the presence of anaphors. Reference [12] posit that the anaphors (reflexives and reciprocals) exist in Maa language. [12] argues that the few reflexives in Maasai occur as independent lexical items whose function is emphasis. This is unlike Dholuo where the reflexive is bound to the verb. The reflexives in Maasai are pronouns which refer back to the antecedent in a construction. Maasai has two forms of reflexive; singular wan 'self' and plural ate 'selves'. Another form of reflexive openy 'self' is used in Maasai to refer to both animate and inanimate argument. On the other hand, reflexive wan 'self' refers to 
animate arguments only. In Maasai, there is, therefore, specification of roles on which singular reflexive should be used which lack in Dholuo. This is represented as in (8):(8)

a. E-tu-duny-o Jonii Kewani

He cut John self

'John cut himself.'

b. E-isuj-a ilayiok $_{\mathrm{i}}$ ate $_{\mathrm{i}}$

They wash boys selves

'The boys washed themselves.'

c. E-ewuo papa openy

He father come self

'My father came himself.'

In example (8a), the reflexive wan 'self' is attached to the third person ke 'him'. This reflexive refers back to the antecedent John who cut a part of his body. In (8b), the reflexive ate 'selves' and antecedent 'boys' corefer. In example (8c) the reflexive openy 'self' refers back to the antecedent father and it is used in the singular. According to [12], the reflexive in Maasai is common with inherent reflexive verbs and natural verbs. This is also true of Dholuo which has inherent reflexives and natural verbs that show an action happening to self like loving oneself. Besides, in Maasai the plural reflexive ate 'themselves/each other' is employed as a reciprocal which is similar to Dholuo that uses the plural reflexive -re 'each other/themselves' as the reciprocal. Another form of reciprocal oopeny 'each other' is used in Maasai. Consider (9):(9)

a. e-isuj-a ilayiok $_{\mathrm{i}}$ oopeny $_{\mathrm{i}}$

they wash boys selves

'The boys are washing themselves/each other.'

b. enyorr inkera ate $_{i}$

love children themselves/each other

'Children love themselves/each other.'

c. $\mathrm{Kewan}_{\mathrm{i}}$ e-to-rony-o enkayioni $\mathrm{i}_{\mathrm{i}}$

Himself trim he boy

'The boy trimmed his hair himself.'

d. $*^{*}$ openy $_{\mathrm{i}}$ e-ta-rony-o enkayioni $\mathrm{i}_{\mathrm{i}}$

Himself trim he boy

Intended: The boy trimmed himself.'

In example (9d), the reciprocal oopeny 'each other' refers back to the antecedent boys while in (9e) ate 'each other' refers back to antecedent children. Moreover, the use of wan as a reflexive marker in Maasai to mean self can be equated to Dholuo use of wuon to mean 'self' and is also used for emphasis. Besides the $-r$ anaphor already discussed, Dholuo also uses the anaphoric wuon 'self' to mean something happening to someone or something. The anaphor wuon 'self' is attached to a personal pronoun which it must agree with in terms of number and person. This anaphoric wuon 'self' in Dholuo in most cases, is used for emphasis on action done to self. The anaphor wuon 'self' in Dholuo bear some resemblance to Maasai's wan 'self' which is a cognate Nilotic language. Though this is not the main item of study in this paper, it is worth noting that there is resemblance in the use of this anaphoric element with Dholuo wuon 'self' in (10). (10)

a. Achwanyora awuon

I hurt self I self

'I hurt myself myself.'

b. Gigore giwuon

They fight they self

'They fought themselves themselves.'

In (10a) the anaphor wuon 'self' emphasizes the reflexive -re 'myself' that refers back to antecedent $a$ - 'I' the person who hurt himself or herself. The use of wuon 'self' is to emphasize that no one else was involved. Example (10b) indicates that reflexive -re 'themselves' refers back to the antecedent gi'they'. The occurrence of the anaphor wuon 'self' attached to the pronoun $g i$ 'they' is to emphasize that the act of fighting was taking place among a specified group of people. Their intention for fighting, though, is not known. Moreover, it is worth noting that in all the constructions in Dholuo, where the anaphor $-r$ 'self' or 'each other' appears in the main sentence, the use of wuon 'self' is dependent on the anaphor and person used. This is contrary to Maasai, a Nilotic language, where the anaphoric wan 'self' is used to refer to the action happening to self or to each other.

In addition, the reciprocal in Maasai is marked by the plural reflexive ate and oopeny 'themselves/each other' [12]. This is different from Dholuo reciprocal which is marked the same way as the reflexive. This is seen in (12):(12)

a. e-isuj-a ilayiok oopeny $_{\mathrm{i}}$

they wash boys selves

'The boys are washing themselves/each other.'

b. enyorr inkera ${ }_{i}$ ate $_{i}$

love children themselves/each other

'Children love themselves/each other.'

Another interesting observation is that in Maasai (13a) below, the anaphor wan 'self 'occupies the subject position meant for the antecedent and the sentence is grammatical. This is because of its function of emphasis. In contrast, (13b) is ungrammatical and the reflexive openy 'self' violates Binding Principle A. The reflexive openy and reciprocal oopeny cannot occupy subject position in Maasai [12]. On the contrary, Dholuo anaphors occupy object positions only and not subject 
positions. Any anaphor that occupies subject position makes the sentence ungrammatical since the anaphor lacks reference or antecedent.(13)

a. Kewan $_{\mathrm{i}}$ e-to-rony-o enkayioni $\mathrm{i}_{\mathrm{i}}$

Himself trim he boy

'The boy trimmed his hair himself.'

b. *openy ${ }_{\mathrm{i}}$ e-ta-rony-o enkayioni $\mathrm{i}_{\mathrm{i}}$

Himself trim he boy

Intended: The boy trimmed himself.'

\subsection{Dholuo Anaphoric Pronouns}

There are pronouns that function as anaphors in a sentence. These pronouns refer back to the antecedent in the sentence are and in some studies referred to as long distance or logophors [26]. This is because they do not occur in the same Inflectional Phrase (IP) with the antecedent and neither are they adjacent. Instead, these pronouns are far apart from the antecedent. The most important thing is that these pronouns have some anaphoric function. In Dholuo, we have personal pronouns and demonstratives that play that role as demonstrated in section 3.2.1 below.

\subsubsection{Personal Pronouns}

A number of African languages are known to have particular forms of pronouns that are used to refer to an antecedent whose speech emotions, or thoughts are being reported. These forms of pronouns are the long distance ones [5]. Similarly, it was noted in a study done on the Yoruba pronominal anaphor Oun 'he/she', that the pronoun can function as an anaphor [14]. [14] refers to these pronouns as a logophors. In contexts, the logophoric pronoun is used to indicate reference to the person whose utterance, thoughts and perceptions are reported. These logophoric pronouns are determined by pragmatic factors. The logophorics are anaphors bound outside their local domain, hence they violate Chomsky's Binding Principle A. They also do not obey the C-command condition. They behave like long distance anaphors that are not bound within their local domain. Data (14) demonstrates the anaphoric pronouns in Dholuo.

a. Apondi oneno ng'ato mane ogoye.

Apondi see person who beat her

'Apondi saw the person who beat her.'

b. Otieno oleko ni en gi nyamburko.

Otieno dream that him has car

'Otieno dreamt that he has a car.'

c. Nyithindo owacho ne baba ni gituo.

Children say to father that they sick
'The children said to their father that they were sick.'

d. Atieno oterone Auma lawe.

Atieno take her Auma clothes.

'Atieno took to Auma her clothes.'

In (14a) the pronoun $-e$ 'her' attached to the verb go 'beat' refers to the person, antecedent Apondi who was affected by the action of beating. In (14b), the pronoun en 'he' refers to the antecedent Otieno who dreamt that he has a car. In example (14c), the pronoun $g i$ 'they' refer to the antecedent children who tell their father that they are sick. (14d) the pronoun - $e$ 'her' in law 'clothe' refer to antecedent Atieno and not Auma.

\subsubsection{Demonstrative Pronouns}

Dholuo demonstrative $n i$ 'that' or mano 'that' can be used to refer back to the subject, antecedent being talked about. The demonstrative pronoun points back to something earlier mentioned. It, therefore, can be used anaphorically to refer to something mentioned earlier. This is demonstrated in (15)

a. Tina owachoni Bob ochwore.

Tina say that Bob stub self

'Tina said that Bob stubbed himself.

b. Atieno owacho ni $\mathrm{a}_{\mathrm{i}}$-puko nyuka, mano $\mathrm{i}_{\mathrm{i}}$ ok atimo

Atieno says that I spill porridge that I have not done

'Atieno says that I have spilt porridge but that I have not done.'

In example (15a), the demonstrative $n i$ 'that refers to antecedent Tina describing the act of Bob intending to stub himself. In (15b), the demonstrative mano 'that' refers back antecedent $a$ - 'I'. Mano 'that' is coindexed with $a$ - 'I' attached to the verb puko 'pour' and not Atieno. This is because Atieno is higher up in the clause.

\subsection{Dholuo Anaphors and Case Theory}

Dholuo data reveals that anaphors occur as objects in constructions. The anaphors must agree in person and gender with the antecedent in the sentence and in assignment of case to be grammatical. This is explained further using Case Theory in section 3.3.1 below.

\subsubsection{Anaphors and Case Assignment}

Case Theory operates under Government Theory. The theory deals with the nature of abstract case relations and their realizations and assignment of case markers [1], [21]. The different arguments that occur in the sentence are assigned case by the case assigners (Verb, Inflection, Preposition) in order to fulfil the case filter principle. For an argument to be assigned accusative case, it must occupy object position while 
nominative case must be assigned to argument in the subject position.

In the same vein, case assignment can either be morphological or abstract. We assume that all arguments are assigned case. These arguments assume different positions in the sentence which may make the sentence grammatical or ungrammatical. Also, the usage of the arguments in the sentence may make them to either change form or not. Thus, when an argument changes its form to a different form which relates to its initial form in object and subject positions, we say that morphologically it has changed. The different forms the argument attains as it changes position are assigned morphological case. On the other hand, if an argument retains its initial form, it is assumed to be abstract, hence it can attain different morphological status and assigned abstract case.

Reference [21] alludes that case is assigned under government where the grammaticality of anaphors is determined by government. The antecedents must govern the anaphors within the minimal IP. Accusative case is assigned by a governing $\mathrm{V}$, or $\mathrm{P}$, nominative case is assigned by INFL, under government or by specifier- head agreement. The subjects of small clauses are case marked by an outside governor. Case assignment is a structural property of verbs, prepositions and INFL containing (AGR)eement. Since case is assigned under government, the antecedent must govern the anaphor in the same minimal IP [21]. Any violation of this rule makes the sentence ungrammatical and assignment of case becomes difficult. Consider (16):

a. Peter ${ }_{i}$ onegore $_{i}$

Peter kill self

'Peter has killed himself.'

b. Mine $_{\mathrm{i}}$ limore $_{\mathrm{i}}$

Women visit each other

'Women visits each other/themselves.'

c. ${ }^{*}$ limore $_{\mathrm{i}}$ mine $_{\mathrm{i}}$

visit each other they

'visits each other women.'

d. $* \mathrm{re}_{\mathrm{i}}$ limo $_{\text {mine }}$

each other visit women

'each other visit women.'

The antecedent, NP Peter in (16a) is assigned a nominative case by INFL while the verb nego 'kill' assigns an accusative case to the anaphor $-r$ 'himself' morphologically. This is because the anaphor $-r$ 'self' is attached to the personal pronoun $-e$ 'him' which when used in the subject position changes to $o$ - 'he' to read onegore 'he killed himself'. If this anaphor -re 'himself' was replaced with Peter to read Peter onego Peter 'Peter killed Peter', the second Peter in the object position assumes an abstract case and is assigned an accusative case since there is no change in form. The anaphor -re 'himself' assumes a morphological case which is a realization of the abstract case Peter, the antecedent which it refers back to. In example (16b), the argument, antecedent mine 'women' is assigned an abstract nominative case by INFL, while the verb limo 'visit' assigns an accusative case to the reciprocal -re 'each other' morphologically. The reciprocal $-r e$ is attached to the personal pronoun $-e$ 'them' which when used in subject position assumes gi- 'they' to read gilimore 'they visit each other'. There is, therefore, change of form in the anaphor, hence the morphological case marking. Examples (16c) and (16d) marked with asterisk are ungrammatical. In (16c), the verb occupies the subject position that INFL should assign nominative case abstractly. The antecedent that the anaphor refers to is at the object position. This makes case assignment difficult. In (16d), the anaphor -re 'themselves' which requires a reference (antecedent) occupies the subject position and it cannot be assigned case by INFL. Consequently, (16c) and (16d) violates government in that the antecedent does not govern the anaphor in the minimal clause. This is demonstrated in fig. 1

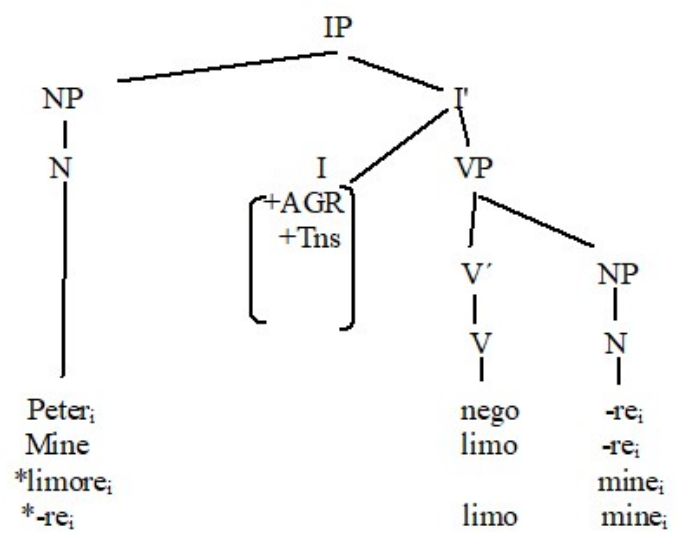

Fig. 1: Relationship between anaphors and antecedent

Fig. (1) indicates the relationship between the anaphors and their antecedents. The subscripts (i) are used to indicate that the NPs refer to the same thing. In Peter onegore 'Peter killed himself', the verb nego 'kill' C- commands the object NP -re 'self'. This object NP which is adjacent to the verb refers back to the subject NP as shown using the subscript. The subject NP Peter is assigned a nominative case by virtue of specifierhead agreement between the subject NP and INFL. The anaphor $-r e$ 'self' is assigned a morphological case by the verb since it refers back to the antecedent Peter. Mine limore 'women visit each other' means that the women perform the act of visitation to one another. The verb limo 'visit' assigns accusative case to anaphor $-r e$ 'each other' morphologically. 
The antecedent mine 'women' is assigned a nominative case by INFL. The reciprocal $-r e$ 'each other' and its antecedent mine 'women' occur in the same minimal IP and they corefer as they are coindexed.

In the same vein, there is a particular structural relationship between the case assignor and assignee. This structural case assignment depends on government while inherent case assignment depends on theta role assignment and government. Subjects of finite clauses have nominative case while NPs that are subjects of infinitival clauses appear in the accusative. A verb cannot assign accusative case to an NP outside the VP such as the sentence subject [11]. The case assigner and the element to which case is assigned should be adjacent. The adjacency condition requires that case assigners are not separated from the NPs which they case-mark by intervening material. But, when case is assigned in a specifier-head agreement configuration, the adjacency condition is not relevant [11]. Consider the following example:

a. $\quad$ Auma $_{\mathrm{i}}$ ohero Mary $_{\mathrm{j}}$
Auma love Mary
'Auma loves Mary.'
b. Auma $_{\mathrm{i}}$ ohere $_{\mathrm{j}}$
Auma love her 'Auma loves her.'
c. $\quad$ Auma $_{\mathrm{i}}$ oherore
Auma love self
'Auma loves herself.'
d. $\quad$ Omondi ${ }_{\mathrm{i}}$ oyuayo san kochike $\mathrm{i}_{\mathrm{i}}$
Omondi pull plate towards him (self)
'Omondi pulled the plate towards himself.'

Examples (17a) and (17b) are cases of Referential expression and pronoun respectively. In (17a), the verb hero 'love' assigns Auma the nominative case, Mary the accusative case. This satisfies the case filter principle and the verb is also adjacent to the NP. The verb hero 'love' in (17b) case marks the NP $-e$ 'her' and assigns the NP accusative case. In (17c), the verb hero 'love' occurs adjacent to anaphor -re 'herself' and also governs it. The verb hero 'love', therefore assigns an accusative case to anaphor, NP -re 'herself'. Chomsky (1981) states that a verb assigns case to an NP that it governs if and only if it assigns a theta role to it. The verb hero 'love' in $(17 \mathrm{~b})$ and $(17 \mathrm{c})$ governs the NPs $-e$ 'her' and $-r e$ 'herself' respectively and also assigns a thematic role to them and their subjects, antecedent Auma. Thus, the verb hero 'love' assigns an accusative case to the anaphors $-e$ 'her' and $-r e$ 'herself'. In addition, in (17b) and (17c), INFL (I) assigns a nominative case to the subject Auma. The difference between assignment of case in (17b) and (17c) is that in (17b) the verb assigns an abstract case to the pronoun since it changes form and refers to someone else, not Auma. Besides, in (17c) the verb assigns a morphological case to the anaphor which gets its referent from the antecedent, Auma. In example (17d), the preposition kochiko 'towards' case marks the NP $-e$ 'him' which act as an anaphor in this case as it refers back to antecedent Omondi and assigns it an oblique case because prepositions assign oblique case to NPs (anaphors). The verb yuayo 'pull' assigns an accusative case to the object san 'plate' while INFL assigns a nominative case to the subject Omondi. These examples indicate that the verb (transitive), INFL and the prepositions are case assigners.

According to the definition of government, the preposition kochiko 'towards' in (17d) case marks the NP $-e$ 'him' because the prepositional phrase (PP) is the maximal projection, and hence a barrier. The closest governor assigns case, that is, the minimality condition on government. This condition states that:

A governs B if and only if

$\begin{aligned} \text { i. } & \text { A is a governor } \\ \text { ii. } & \text { A m-commands B } \\ \text { iii. } & \text { There is no node } Z \text { such that } \\ \text { iv. } & Z \text { is a potential governor for B } \\ \text { v. } & Z \text { C-commands B } \\ \text { vi. } & \text { Z does not C-command A }\end{aligned}$

This information on the minimality condition is represented diagrammatically in fig. 2 below.

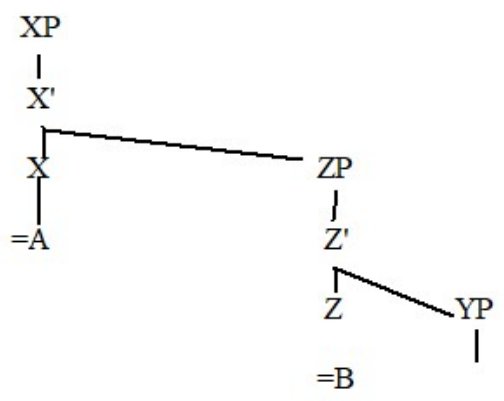

Fig. 2: Minimality Condition

Consequently, case assignment requires both the C-command and m-command requirements where the concepts of dominating and maximal projections are key [21]. For these two concepts to work, there is need for a barrier. This is demonstrated in (18):

(18)

Paka $_{\mathrm{i}}$ odumbore $_{\mathrm{i}}$ e dapi

Cat plunge self in water pot

'The cat plunged itself in the water pot.'

The verb dumbo 'plunge' assigns an accusative case to the anaphor $-r e$ 'itself', the antecedent paka 'cat' is assigned 
nominative case by INFL, while the preposition $e$ 'in' assign an oblique case to the object dapi 'water pot'. The verb dumbo fall' attempts to assign an accusative case to the object dapi 'water pot', but is blocked by the preposition $e$ 'in. As earlier discussed, maximal projections are barriers and so the PP where $e$ 'in' occurs blocks the verb dumbo 'plunge' from assigning the object dapi 'water pot' case. This is represented structurally in fig. 3 :

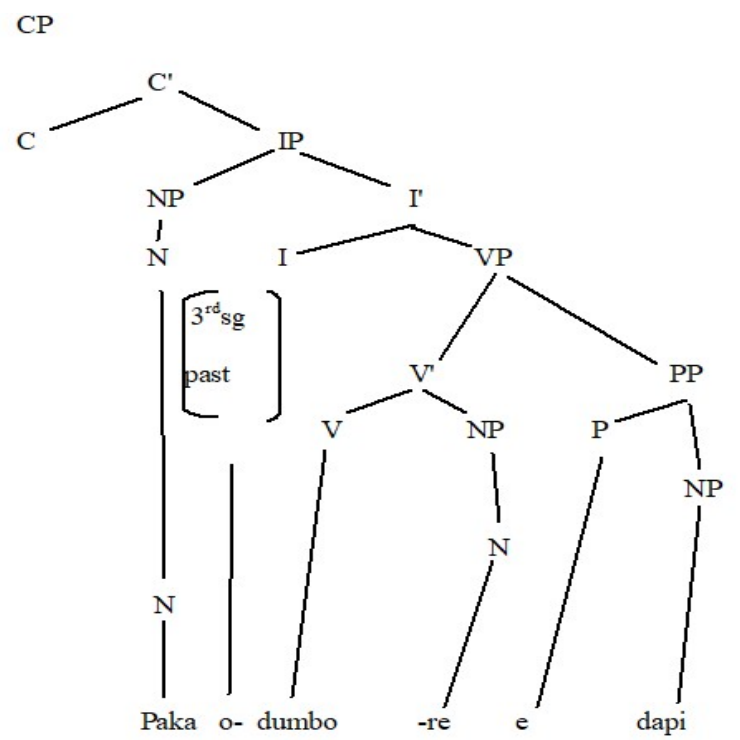

From fig. 3, the verb dumbo 'plunge' m-commands the NP dapi 'water pot'. The first maximal projection dominating dumbo 'plunge' is VP, and VP does dominate the NP dapi 'water pot'. Therefore, if case assignment depends on $\mathrm{m}$ command only, we have a problem. This is because the object of the preposition dapi 'water pot' need to receive case from the preposition. How then do we protect the object dapi 'water pot' from being assigned case by the verb dumbo 'plunge'? To do this, we assume that the maximal projections are barriers to government and as barriers their heads which are case assignors' controls elements to be case marked. Therefore, case assignment from outside the maximal projection is barred [21]. In essence, even though the verb dumbo 'plunge' still m-commands the object dapi 'water pot' of the preposition, it cannot assign case to it because of the intervening barrier PP.

\subsubsection{Anaphors and Exceptional Case Making (ECM)}

We have seen that maximal projections which are barriers like PP blocks the assignment of case to anaphors. However, there are exceptions where the rules may be violated and the anaphor assigned case outside the minimal IP. This applies to infinitival IP which do not constitute to be a barrier for outside government. This is because the infinitival IP lacks agreement features. It can, therefore, case mark an NP outside its governing category. Such situations are unique and exceptional and are acceptable within a language. Let us consider example (19): (19)

Daudi $_{i}$ paro en oherore ${ }_{i}$

Daudi think him love self

'Daudi thinks himself to be lovable.'

The example in (19) is an instance of Exceptional Case Marking (ECM). ECM applies to infinitival IP which do not constitute a barrier for outside government and to case assignment [21] though it is a maximal projection. The reason being that infinitival IP lacks person, number and tense features. It also does not assign nominative case. We need the subject, antecedent of the IP to be exceptionally case marked with accusative case from the matrix verb. If the Complementiser Phrase (CP) is present, then ECM is blocked by this barrier. In (19), the verb paro 'think' does not assign an accusative case to en 'himself' since it is in a higher clause and en 'he' is not the direct object of the verb paro 'think'. The NP en 'he' is the subject of the lower infinitival clause. We have noted that infinitival IP does not assign case since it lacks the features number and person, so not a barrier. Therefore, the verb hero 'love' does not assign accusative case to the anaphor $-r e$ 'himself since it is an infinitival IP. The anaphor $-r e$ 'himself' is thus assigned accusative case by the verb paro 'think' from the higher clause to get its reference from the subject (antecedent) Daudi, which is assigned nominative case by INFL hence Exceptional Case Marking on the anaphor. This is represented in fig. 4:

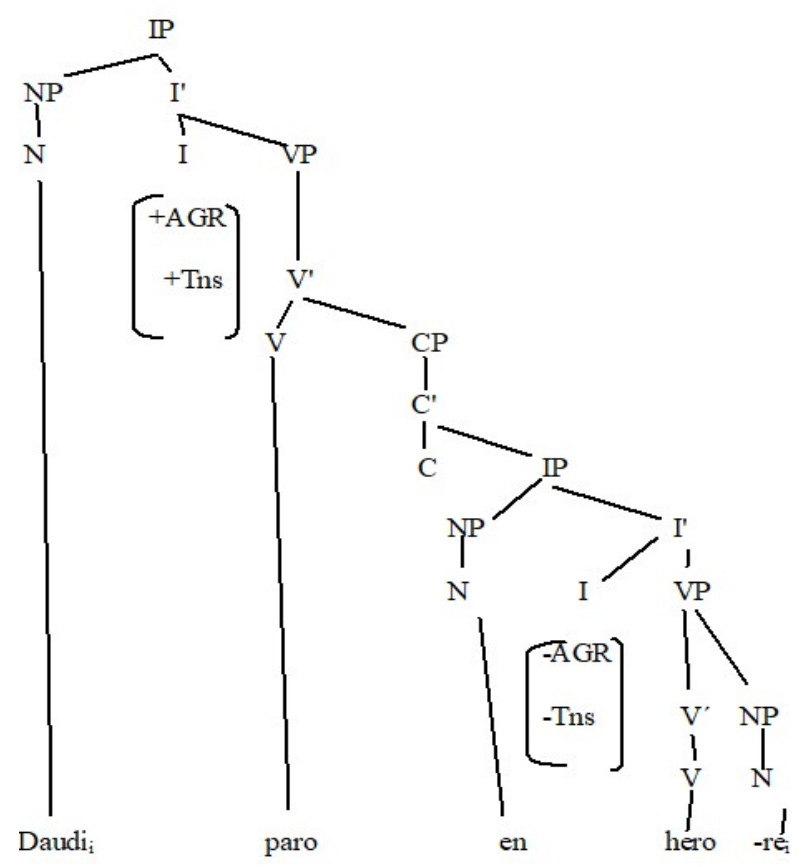

Fig. 4: Exceptional Case Marking

However, Exceptional Case Making poses problems to some anaphoric sentences that appear in different contexts. The 
presence of the CP as a barrier prevents ECM [21]. Example (20) presents two sentences uttered in different contexts. Their different interpretations can best be explained structurally.

a. Adoyo ong'eyo ni Akinyi $i_{i}$ ohero umore ${ }_{i}$

Adoyo know that Akinyi love cover self

'Adoyo knows that Akinyi loves covering herself.'

b. * Adoyo $_{i}$ ong'eyo ni Akinyi ohero umore ${ }_{i}$

Adoyo she know that Akinyi love cover self

'Adoyo knows that Akinyi loves covering herself.'

In example (20a), the sentence is grammatical because, Akinyi, antecedent is assigned a nominative case by INFL and anaphor $-r e$ 'herself' is assigned accusative case by the verb hero 'love' since they are in the same minimal IP. The verb $n g$ 'eyo 'know' cannot assign case to the anaphor $-r e$ 'herself' in (20a) because of the presence of barrier CP and also the anaphor -re 'herself' does not co-refer with the subject of this verb. Example (20b) though sounds grammatical, is ungrammatical since the anaphor -re 'herself' is coindexed with antecedent Adoyo and they are not within the same minimal IP, which is a violation of Binding Principle A. Adoyo C-commands Akinyi oumore 'Akinyi has covered herself' which may seem to be grammatical. But, there is the maximal projection $\mathrm{CP} n i$ 'that' which blocks the INFL from the IP Akinyi oumore 'Akinyi has covered herself' to assign a nominative case to the subject, antecedent in IP Adoyo ongeyo 'Adoyo knows'. The verb hero 'love' assigns accusative case to anaphor -re 'herself' but lacks a referent, antecedent in the minimal IP Akinyi oumore 'Akinyi covers herself'. Example (20b) indicates that ECM cannot occur because of the presence of the barrier, CP. This is represented in fig. 5:

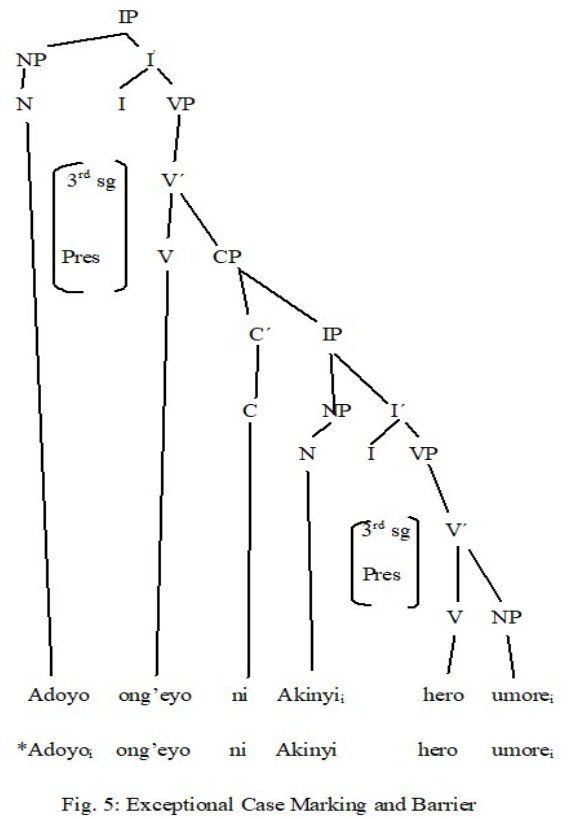

\section{CONCLUSION}

In conclusion, it is worth noting in this paper that Dholuo has only one anaphor representation $-r$ 'self' or 'each other' which occur in object position. When Dholuo anaphor occupies the subject position, it violates Chomsky's Binding Principle A. The other elements that function as anaphor change depending on the context. Dholuo anaphor is assigned morphological accusative case while the antecedent is assigned nominative abstract case. There are cases of Exceptional Case Marking (ECM) of the anaphor and antecedent when the IP is infinitival. The anaphor, subject of the infinitival IP is exceptionally assigned accusative case from the matrix verb. But, ECM does not apply in the presence of PP and CP which are barriers to government. Lastly, the anaphoric wuon 'self' only occur with the presence of anaphor $-r$ 'self' or 'each other' and it, therefore, cannot be assigned case. Its function is only for emphasis. If case is assigned to wuon 'self' it would be a violation of the case filter principle. The implication is that this second anaphor is left out while it is important when used in certain context. There is need to assign case to this second anaphoric wuon 'self' with an appropriate linguistic theory.

\section{REFERENCES}

[1] Aarts, B. (2008). English syntax and argumentation ( ${ }^{\text {nd }}$ ed). London: Palgrave Macmillan.

[2] Akanbi, T.A. (2014). Descriptive and syntactic analysis of Àhàn pronouns (Vol 4. pp. 664-675). Retrieved from Open Journal of Modern Linguistics. Doi:10.4236/OJML.2014.45057

[3] Alexiadou, A \& Schäfer, F. (2014). Towards a non-uniform analysis of naturally reflexive verbs. Robert, E Santana-La, B (Eds), Proceedings of the $31^{\text {st }}$ west coast conference on formal linguistics (pp. 1-10). Somerville, MA: Cascadilla Proceedings Project.

[4] Shiraki, H. (2005). Anaphors, agreement and case. Retrieved from http://www.phon.UCL.ac.uk/publication/WPL/04 papers/ Shiraki.pdf

[5] Asudeh, A. (2008). Anaphora and argument structure: Topics in the syntax and semantics of reflexives and reciprocals. Retrieve from https://www.researchgate.net/publication/268441751.

[6] Barasa, D. (2017). Ateso grammar: A descriptive account of an eastern nilotic language. Münchem: Lincom Academic Publishers.

[7] Chomsky, N. (1981). Lectures on government and binding. Berlin: Dordrecht: Foris Publications.

[8] Diercks, M \& Sikuku, J. (2013). Clitics in bantu language: Deriving pronominal incorporation in lubukusu. Retrieved from https:research.ponoma.edu/mjkd/files/2020/07/BukusuOM.9.15.20 13.pdf

[9] Gluckman, J. (2018). Reciprocals and plural events in logoori. In association of contemporary African linguists (49). Michigan: Michigan State University.

[10] Government of Kenya. (2019). The 2019 Kenya population and housing census results. Retrieved from https://www.knbs.or.ke

[11] Haegemann, L. (1994). Introduction to government and binding theory $\left(2^{\text {nd }} \mathrm{ed}\right)$. Blackwell: Oxford University Press.

[12] Karani, M. (2018). Syntactic categories and the verb-argument Complex in Parakuyo Maasai. Unpublished PhD Dissertation, Steden bosch University.

[13] Köng, E \& Volker, G. (2008). Trends in linguistics: Reciprocals and reflexives. Berlin: Mourton De Gruyter \& Co.

[14] Lawal, N. (2006). Yoruba Pronominal anaphor Ǒun and the binding theory. In Mugame, $\mathrm{J}$ et al (Eds.) Selected proceedings of the $35^{\text {th }}$ annual conference on African linguistics, (pp. 245-257). Somervile MA: Cascadilla Proceedings Project. 
[15] Madara, M.A. (1989). The analysis of pronominal and anaphors in Dholuo: A government and binding approach. Unpublished MA dissertation, University of Nairobi.

[16] Nedjalkov, V. ed. (2007). Reciprocal constructions. Amsterdam: John Benjamin Publishing Company.

[17] Okoth, D. (1986). Dholuo morphophonemics in a generative framework. Berlin: Dietrich Reimer Verlag.

[18] Okoth, D. (1997). A functional grammar of Dholuo. Köln: Rudiger köppe Verlag.

[19] Omondi, L.N. (1982). The major syntactic structures of Dholuo. Berlin: Dietrich Reimer Verlag.

[20] Onyango, J.A. (2013). A semantic analysis of Dholuo anaphors in simple declarative sentences: The Minimalist Program Perspective. Unpublished MA Thesis, University of Nairobi.

[21] Poole, G. (2000). Modern linguistics syntactic theory $\left(2^{\text {nd }}\right.$ ed). New York: Palgrave Publishers.

[22] Reuland, E. Schandler, D (2010). Approaching body part reflexives.Utrecht Institute of linguistic: Utrecht University.
Retrieved

from http://www.africananaphora.rudgers.edu/index.php.

[23] Schladt, M. (2000). The typology and grammaticalization of reflexives: In Zygmuny, F \& Curl, T (Eds.) Forms and Functions. Amsterdam: Benjamins.

[24] Siemund, P. (2018). Speech acts and clause types: English in a cross linguistics context. United Kingdom, UK: University Press.

[25] Sikuku, J. (2010a). Syntactic patterns of anaphoric relations in lubukusu: Representation and interpretation in a minimalist perspective. Unpublished PhD Thesis, University of Nairobi.

[26] Sikuku, J. (2010b). An examination of anaphoric relations in selected African languages. Retrieved from http://www.africananaphora.rudgers.edu/index.php.

[27] Wambia, R. J. A. (2015). A syntactic interpretation of ambiguous Dholuo long distance anaphors. Unpublished MA Thesis, Maseno University.

[28] Zeller, J. (2011). The syntax of African language: A review. Ms. Kwazulu-Natal: University of Kwa-Zulu-Natal. 